\title{
Adsorption of Chromium (VI) from Aqueous Solution Using Zeolite/Chitosan Hybrid Composite
}

\author{
Meiling Pang ${ }^{1}$, Naoki Kano ${ }^{2 *}$ and Hiroshi Imaizumi ${ }^{2}$ \\ 1. Graduate School of Science and Technology, Niigata University, Niigata 950-2181, Japan \\ 2. Department of Chemistry and Chemical Engineering, Faculty of Engineering, Niigata University, Niigata 950-2181, Japan
}

\begin{abstract}
This study investigated the adsorption ability of ZCHC (zeolite/chitosan hybrid composite) as adsorbent for chromium $(\mathrm{Cr}(\mathrm{VI}))$, ZCHC was prepared with sol-gel method by mixing zeolite and chitosan. Adsorption experiment from aqueous solutions containing known amount of $\mathrm{Cr}(\mathrm{VI})$ using zeolite, chitosan and ZCHC was explored to evaluate the efficiency of ZCHC as adsorbent for $\mathrm{Cr}$ in a batch system. The amount of $\mathrm{Cr}(\mathrm{VI})$ adsorbed at different $\mathrm{pH}$ values, initial concentrations, adsorbent dosages, and contact times were determined by ICP-AES (inductively coupled plasma-atomic emission spectrometry) in order to determine the optimum conditions for $\mathrm{Cr}(\mathrm{VI})$ adsorption. Furthermore, the adsorption mechanism of $\mathrm{Cr}(\mathrm{VI})$ by zeolite, chitosan and ZCHC was investigated by applying Langmuir and Freundlich isotherm equations to the data obtained. In addition, the rates of adsorption were found to conform to pseudo-second order kinetics.
\end{abstract}

Key words: Adsorption, chromium, zeolite, chitosan, hybrid composite, adsorption isotherms, kinetics.

\section{Introduction}

Contamination of toxic metals in the aquatic environment is one of the most debatable problems in the world with industrial development [1,2]. Heavy metals are considered to be potentially hazardous and can cause physiological and neurological disorders [3-5].

$\mathrm{Cr}$ consists of two stable oxidation states such as trivalent state $\mathrm{Cr}(\mathrm{III})$ and hexavalent state $\mathrm{Cr}(\mathrm{VI})$ in natural aqueous environment. It is well known that, $\mathrm{Cr}(\mathrm{III})$ is essential materials for living organisms, whereas, $\mathrm{Cr}(\mathrm{VI})$ is more toxic, carcinogenic and mutagenic, is considered as severe pollutant due to high water-solubility and toxicity [6-10]. The maximum levels permitted in wastewater are $5 \mathrm{mg} \cdot \mathrm{dm}^{-3}$ for trivalent and $0.05 \mathrm{mg} \cdot \mathrm{dm}^{-3}$ for hexavalent chromium [11].

Natural zeolites have been used as cationic exchange materials for the remediation of heavy metals and other contaminants due to their excellent properties as adsorbents. They also have the

\footnotetext{
*Corresponding author: Naoki Kano, associate professor, research fields: environmental chemistry and environmental preservation.
}

advantages of being very abundant in nature and possessing high chemical stability.

During the last decade, alternative and novel modifications have been exploited to give zeolites new properties that can increase their applications. In fact, modifications with cationic surfactants, such as high molecular-weight quaternary ammonium salts, have rapidly become important because they provide zeolites with the potential to behave as anionic exchangers $[12,13]$.

Among environmentally friendly technologies for the removal of heavy metals from aquatic effluent, biosorption has attracted increasing research interest recently [14-17]. The major advantages of biosorption are its high effectiveness in reducing the heavy metals and the use of inexpensive biosorbents $[9,17]$.

Among many biosorbents, chitosan can be an excellent biosorbent for metals because its amine $\left(-\mathrm{NH}_{2}\right)$ and hydroxyl $(-\mathrm{OH})$ groups may serve as coordination sites to form complexes with various heavy metal ions $[12,13,18]$. Uses of chitosan on the removal of various pollutants have been adequately reviewed [5, 18-24]. 
The scientific literature gives no previous data of removal of $\mathrm{Cr}(\mathrm{VI})$ by $\mathrm{ZCHC}$ (zeolite/chitosan hybrid composite). There are only some articles reporting materials based on chitosan modified with different types of zeolites for removal of nitrates, humic acid, copper ion $[12,17]$. In this paper, the results of adsorption experiment for $\mathrm{Cr}(\mathrm{VI})$ from aqueous solution using $\mathrm{ZCHC}$ was presented to investigate the efficiency of ZCHC as adsorbent for $\mathrm{Cr}$ for more practical use in future.

\section{Experimental Sections}

\subsection{Materials and Reagents}

Chitosan (M.W. (molecular weight) 100,000-300,000) was purchased from ACROS ORGANICS Co. (New Jersey, USA). Zeolite was purchased from Kanto Chemical Corporation, Inc. Zeolite was heated at $700{ }^{\circ} \mathrm{C}$ for $3 \mathrm{~h}$ to activate the surface in a muffle furnace and then washed with hydrochloric acid (5\%, volume) and deionized water (at $80{ }^{\circ} \mathrm{C}$ ) to remove fine powders and contaminants and was then dried at $110^{\circ} \mathrm{C}$ for $2 \mathrm{~h}$ before use.

$\mathrm{Cr}(\mathrm{VI})$ standard solutions were prepared by diluting a standard solution $\left(1,000 \mathrm{mg} \cdot \mathrm{dm}^{-3} \mathrm{~K}_{2} \mathrm{Cr}_{2} \mathrm{O}_{7}\right.$ solution) purchased from Kanto Chemical Co. All other chemical reagents were also purchased from Kanto Chemical Co. All reagents used in this work were analytical grade, and water $(>18.2 \mathrm{M} \Omega$ in electrical resistance) which was treated by an ultrapure water system (Advantec aquarius: RFU 424TA, Advantec Toyo, Japan) was employed throughout the work.

\subsection{Preparation and Characterization of $\mathrm{ZCHC}$}

ZCHC was prepared by mixing solutions of chitosan and dispersions of zeolite in water. First, $1 \mathrm{~g}$ chitosan was dissolved in $20 \mathrm{~cm}^{3}$ of $0.2 \mathrm{M}$ acetic acid with constant stirring at temperature of $50{ }^{\circ} \mathrm{C}$. Then, $10 \mathrm{~cm}^{3}$ of deionized water was added into $10 \mathrm{~cm}^{3}$ chitosan sol solution, and was heated and stirred for $1 \mathrm{~h}$. These solutions were mixed, while zeolite was dispersed in the chitosan solution with constant stirring for $5 \mathrm{~h}$ at a temperature of $50{ }^{\circ} \mathrm{C}$. Then, the solution was transferred into five centrifuge tubes $\left(10 \mathrm{~cm}^{3}\right)$, which were centrifuged at 9,000 rpm for 5 min, and then washed with deionized water to remove contaminants. The mixed solutions were put on Petri dishes, and were left to dry at room temperature for $24 \mathrm{~h}$. The obtained films with a thickness of $0.1 \mathrm{~mm}$ were used for the following adsorption experiments.

The structure of the zeolite, chitosan and ZCHC were carried out by $\mathrm{N}_{2}$ adsorption/desorption tests (Micromeritics TriStar 3020). The BET (Brunaeur, Emmet and Teller) method was applied to determine the surface area. The surface morphology of zeolite, chitosan and ZCHC were surveyed using SEM (scanning electron microscopy, JCM-6000, JEOL).

\subsection{Adsorption Experiment for Cr Using Chitosan and $\mathrm{ZCHC}$}

For investigating the effects of $\mathrm{pH}$, contact time, adsorbent dose and initial concentration on the adsorption of $\mathrm{Cr}(\mathrm{VI})$, the following experiments were performed using zeolite, chitosan and ZCHC. Adsorbent was thoroughly mixed with $50 \mathrm{~cm}^{3}$ of containing known amount of $\mathrm{Cr}(\mathrm{VI})$ in a $200 \mathrm{~cm}^{3}$ conical flask, and the suspensions was shaken in a water bath at room temperature $\left(25 \pm 2{ }^{\circ} \mathrm{C}\right)$. Adsorption experiments were conducted in the $\mathrm{pH}$ range of 2-8, contact time from $1 \mathrm{~h}$ to $24 \mathrm{~h}$, adsorbent dosage $0.1-2.0 \mathrm{~g} \cdot \mathrm{dm}^{-3}$, and initial concentration from 20 to $200 \mu \mathrm{g} \cdot \mathrm{dm}^{-3}$. The $\mathrm{pH}$ of each solution was adjusted by using $0.1 \mathrm{~mol} \cdot \mathrm{dm}^{-3} \mathrm{NH}_{3}$ aq (aqueous solution) $/ 0.1 \mathrm{~mol} \cdot \mathrm{dm}^{-3} \mathrm{HNO}_{3}$.

Following each adsorption experiment, the suspension containing adsorbent and the above standard solution was filtered through a $0.1 \mu \mathrm{m}$ membrane filter (Advantec Mixed Cellulose Ester, $47 \mathrm{~mm}$ ) to remove $\operatorname{Cr}(\mathrm{VI})$ that have been adsorbed into the adsorbent, and the concentration of this metal in the filtrate was determined with an ICP-AES (inductively coupled plasma-atomic emission spectroscopy). 
The metal uptake by the adsorbent was calculated using the Eq. (1):

$$
q=\frac{\left(C_{0}-C_{e}\right)}{W} \cdot V\left(\mathrm{mg} \cdot \mathrm{g}^{-1}\right)
$$

where, $q$ is the adsorption capacities of $\mathrm{Cr}(\mathrm{VI})$ at equilibrium $\left(\mathrm{mg} \cdot \mathrm{g}^{-1}\right), C_{0}$ and $C_{\mathrm{e}}$ are the initial and equilibrium concentrations of $\mathrm{Cr}(\mathrm{VI})$ in a batch system respectively $\left(\mathrm{mg} \cdot \mathrm{dm}^{-3}\right), V$ is the volume of the solution $\left(\mathrm{dm}^{3}\right)$, and $W$ is the dry weight of each adsorbent (g).

\subsection{Langmuir and Freundlich Isotherm Model}

Adsorption isotherms of adsorption data were studied at varying initial concentration from $20 \mu \mathrm{g} \cdot \mathrm{dm}^{-3}$ to $200 \mu \mathrm{g} \cdot \mathrm{dm}^{-3}$ under optimized conditions. Two common adsorption models, Langmuir and Freundlich isotherm models were applied to evaluate the adsorption data obtained for $\mathrm{Cr}(\mathrm{VI})$ based on Dahiya et al. $[2,17]$.

Langmuir model assumes monolayer adsorption onto a surface and is given by:

$$
\frac{C_{e}}{q_{e}}=\frac{C_{e}}{q_{\max }}+\frac{1}{K_{L} q_{\max }}
$$

where, $C_{\mathrm{e}}$ is the equilibrium concentration of $\mathrm{Cr}(\mathrm{VI})$ in the aqueous phase $\left(\mathrm{mg} \cdot \mathrm{dm}^{-3}\right), K_{\mathrm{L}}$ is the Langmuir adsorption constant $\left(\mathrm{dm}^{3} \cdot \mathrm{mg}^{-1}\right)$, and $q_{\mathrm{e}}$ and $q_{\max }$ are the amount of adsorption of $\mathrm{Cr}(\mathrm{VI})$ at equilibrium and maximum adsorption capacity on the surface of adsorbent $\left(\mathrm{mg} \cdot \mathrm{g}^{-1}\right)$, respectively.

On the other hand, the linearized Freundlich model isotherm is represented by the Eq. (3):

$$
\log _{10} q_{\mathrm{e}}=\log _{10} K_{\mathrm{F}}+(1 / n) \log _{10} C_{\mathrm{e}}
$$

where, $K_{\mathrm{F}}$ and $1 / n$ indicate the adsorption capacity and the adsorption intensity of the system, respectively. The plots of $q_{\mathrm{e}}$ versus $C_{\mathrm{e}}$ in $\log$ scale can be plotted to determine values of $1 / n$ and $K_{\mathrm{F}}$ depicting the constants of Freundlich model.

\subsection{Kinetic Studies}

Kinetic models have been proposed to determine the mechanism of the adsorption process, which provide useful data to improve the efficiency of the adsorption and feasibility of process scale-up [3, 14]. In the present investigation, the mechanism of the adsorption process was studied by fitting pseudo first-order and second-order reactions to the experimental data.

The pseudo first-order model is given by the Eq. (4):

$$
\ln \left(q_{e}-q_{t}\right)=\ln q_{e}-k_{1} t
$$

where, $q_{\mathrm{e}}$ and $q_{\mathrm{t}}$ are the adsorption capacities of $\mathrm{Cr}(\mathrm{VI})$ at equilibrium and time $t$, respectively $\left(\mathrm{mol} \cdot \mathrm{g}^{-1}\right)$, and $k_{1}$ is the rate constant of the pseudo-first-order adsorption $\left(\mathrm{h}^{-1}\right)$.

The linear form of the pseudo second-order rate equation is given as follows:

$$
\frac{t}{q_{t}}=\frac{1}{k q_{e}^{2}}+\frac{t}{q_{e}}
$$

where, $k$ is the rate constant of the pseudo-second-order adsorption $\left(\mathrm{g} \cdot \mathrm{mol}^{-1} \cdot \mathrm{h}^{-1}\right)$.

\section{Results and Discussions}

\subsection{Characteristics of $\mathrm{ZCHC}$}

The surface property of zeolite, chitosan and ZCHC were investigated by $\mathrm{N}_{2}$ adsorption, and the analytical results for the adsorption/desorption isotherms are shown in Table 1. The pore volume was calculated from the amount of $\mathrm{N}_{2}$ adsorbed at the relative pressure of 0.99 . The pore size was calculated from the adsorption average pore width ( $4 \mathrm{~V} / \mathrm{A}$ by BET) in this work. The SEM pictures of the chitosan and ZCHC are shown in Fig. 1. By comparing the surface structure chitosan and $\mathrm{ZCHC}$, the zeolite treatment leads to a remarkable increase in the surface area and mesoporous volume of $\mathrm{ZCHC}$ sample. Then $\mathrm{ZCHC}$ can be a good adsorbent for $\mathrm{Cr}$.

\subsection{Adsorption of Cr(VI) on ZCHC}

For obtaining the optimum conditions regarding the adsorption of $\mathrm{Cr}(\mathrm{VI})$, the effects of $\mathrm{pH}$, contact time and dosage of adsorbents (i.e., zeolite, chitosan and 
Table 1 Texturals characteristics of adsorbents.

\begin{tabular}{llll}
\hline Adsorbent & $\begin{array}{l}\text { BET surface } \\
\operatorname{area~}\left(\mathrm{m}^{2} \cdot \mathrm{g}^{-1}\right)\end{array}$ & $\begin{array}{l}\text { Pore volume } \\
\left(\mathrm{cm}^{3} \cdot \mathrm{g}^{-1}\right)\end{array}$ & $\begin{array}{l}\text { Pore size } \\
(\mathrm{nm})\end{array}$ \\
\hline Zeolite & 5.63 & 0.0474 & 26.8 \\
Chitosan & 0.612 & 0.00385 & 25.2 \\
ZCHC & 9.25 & 0.0485 & 21.0 \\
\hline
\end{tabular}

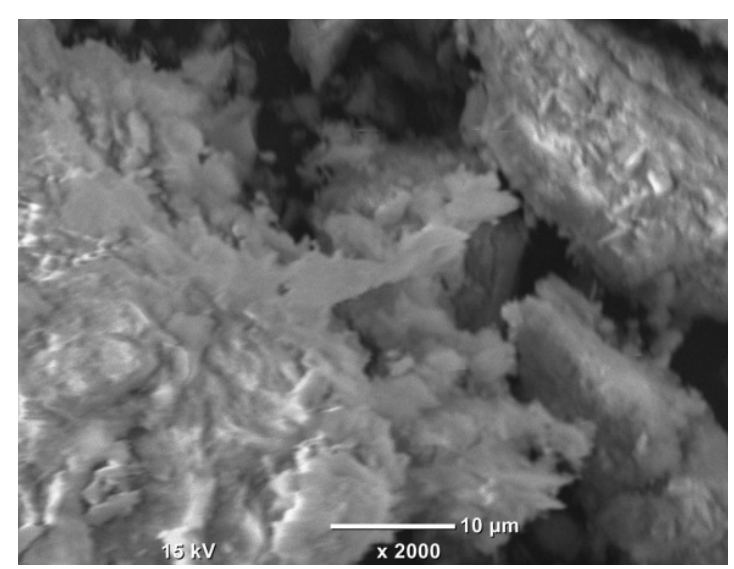

(a)

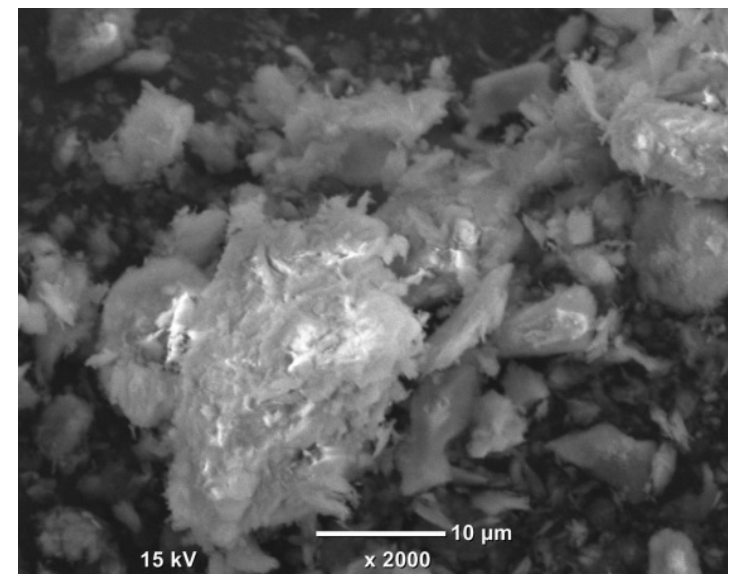

(b)

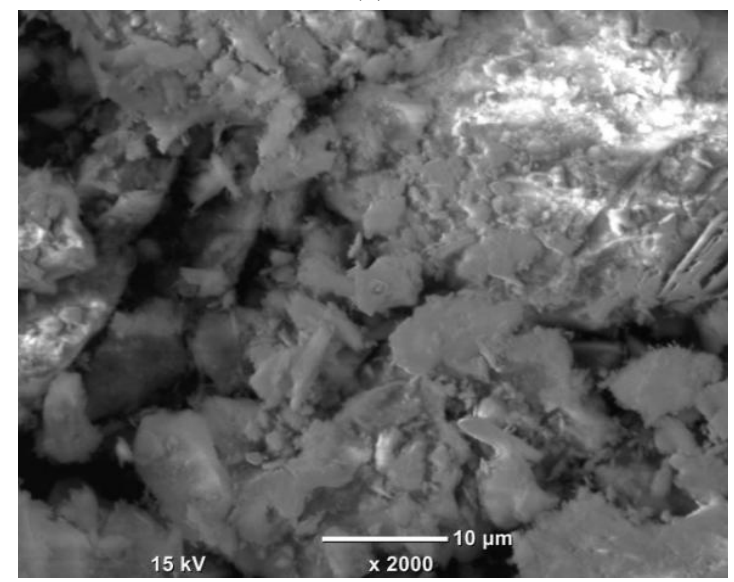

(c)

Fig. 1 SEM images of chitosan and ZCHC (a: Zeolite; b: Chitosan; c: ZCHC).
$\mathrm{ZCHC}$ ) on the removal of $\mathrm{Cr}(\mathrm{VI})$ from the aqueous solution were investigated.

\subsubsection{Effect of $\mathrm{pH}$}

Solution $\mathrm{pH}$ is one of the most important parameters affecting adsorption characteristics. In many cases, the dominant chemical species alter as $\mathrm{pH}$ varies. To investigate the effect of solution $\mathrm{pH}$ on $\mathrm{Cr}(\mathrm{VI})$ removal efficiency by $\mathrm{ZCHC}$, the $\mathrm{pH}$ of the solution was varied from $2-8$ (in $100 \mu \mathrm{g} \cdot \mathrm{dm}^{-3}$ of solution using $1.0 \mathrm{~g} \cdot \mathrm{dm}^{-3} \mathrm{ZCHC}$ dosage for contact time of $6 \mathrm{~h}$ ). The experimental results using $\mathrm{ZCHC}$ are shown in Fig. 2 along with that by chitosan.

$\mathrm{Cr}(\mathrm{VI})$ exists as hydrogen chromate anions $\left(\mathrm{HCrO}_{4}{ }^{-}\right)$between $\mathrm{pH} 2.0$ and $\mathrm{pH}$ 6.5, and it exists as chromate ions $\left(\mathrm{CrO}_{4}{ }^{2-}\right)$ at $\mathrm{pH} 8$ according to the following Eqs. (6-8) [25-27]:

$$
\begin{gathered}
\mathrm{HCrO}_{4}^{-} \leftrightarrow \mathrm{CrO}_{4}{ }^{2-}+\mathrm{H}^{+} \mathrm{p} K \mathrm{a}=5.9 \\
\mathrm{H}_{2} \mathrm{CrO}_{4} \leftrightarrow \mathrm{HCrO}_{4}^{-}+\mathrm{H}^{+} \mathrm{p} K \mathrm{a}=4.1 \\
\mathrm{Cr}_{2} \mathrm{O}_{7}{ }^{2-}+\mathrm{H}_{2} \mathrm{O} \leftrightarrow 2 \mathrm{HCrO}_{4}^{-} \mathrm{pKa}=2.2
\end{gathered}
$$

The adsorption capacity of $\mathrm{Cr}(\mathrm{VI})$ reached maximum at $\mathrm{pH} 3$ in case of using $\mathrm{ZCHC}$ (whereas at $\mathrm{pH} 4$ for zeolite and chitosan), where $\mathrm{Cr}(\mathrm{VI})$ may exist as $\mathrm{HCrO}_{4}^{-}$or $\left(\mathrm{Cr}_{2} \mathrm{O}_{7}{ }^{2-}\right)$. This anion species has a tendency to bind to the protonated active sites of the chitosan in solution at optimum $\mathrm{pH}$ [23]. Cr(VI) exists as chromate ion $\left(\mathrm{CrO}_{4}{ }^{2-}\right)$ at $\mathrm{pH}$ above 6.5. At $\mathrm{pH} 8$, the uptake capacities are very low. This could be explained as competitiveness between chromate and hydroxyl ions. Then, $\mathrm{pH} 3$ was taken for the removal of $\mathrm{Cr}(\mathrm{VI})$ by $\mathrm{ZCHC}$ (and $\mathrm{pH} 4$ was used for zeolite and chitosan) for further experiments.

\subsubsection{Effect of Contact Time}

The effect of contact time on the adsorption capacity of $\mathrm{Cr}(\mathrm{VI})$ using $1.0 \mathrm{~g} \cdot \mathrm{dm}^{-3}$ adsorbent $\left(100 \mu \mathrm{g} \cdot \mathrm{dm}^{-3}\right.$ of solution) is investigated. 


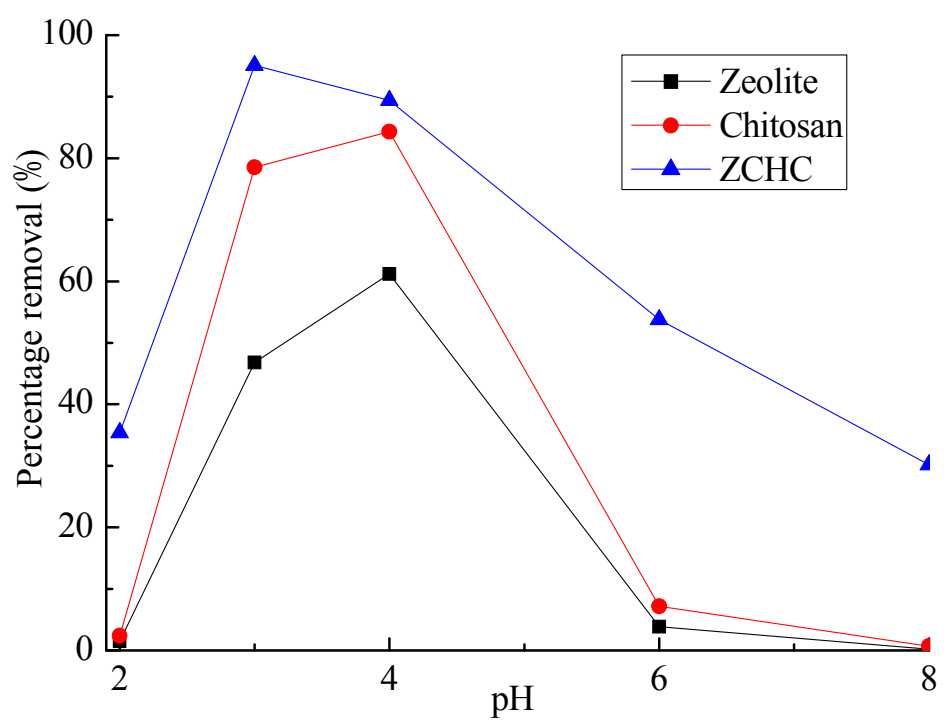

Fig. 2 Effect of pH on percent removal of $\mathrm{Cr}(\mathrm{VI})$ using adsorbents.

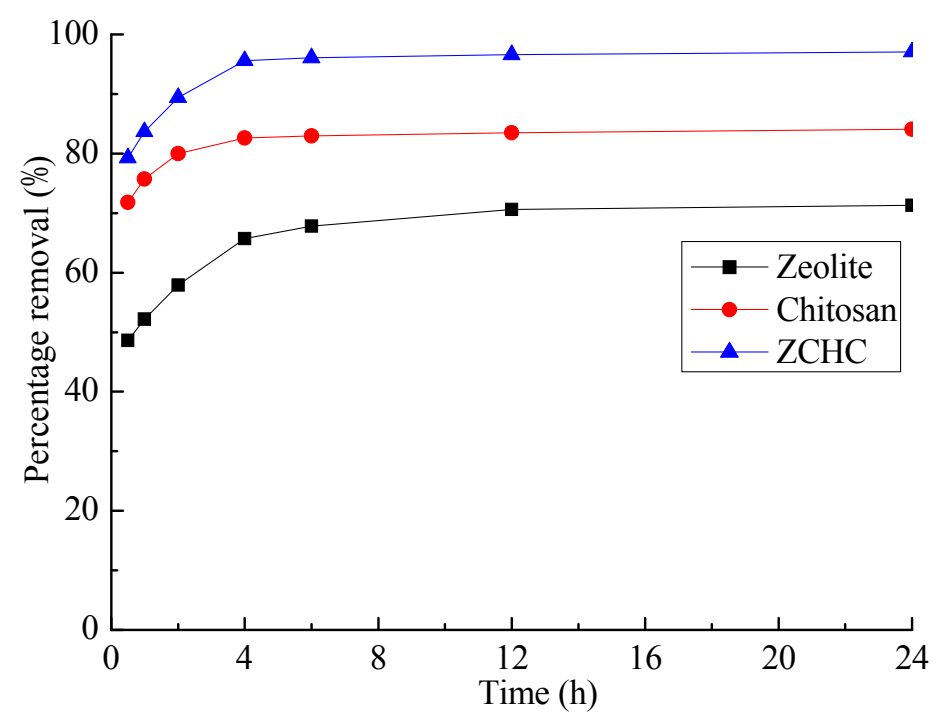

Fig. 3 Effect of contact time on percent removal of $\mathrm{Cr}(\mathrm{VI})$ using chitosan and adsorbents.

The adsorption capacity of adsorbents for $\mathrm{Cr}(\mathrm{VI})$ are shown in Fig. 3. More than 50\% (in case of zeolite), $60 \%$ (in case of chitosan) and $80 \%$ (in case of ZCHC) adsorption was observed within first $30 \mathrm{~min}$, and approximately $80 \%$ (in case of zeolite and chitosan) and $95 \%$ (in case of $\mathrm{ZCHC}$ ) was obtained at $240 \mathrm{~min}$ (i.e., $4 \mathrm{~h}$ ) and after that there is no appreciable increase. Hence, the optimized contact time was taken $4 \mathrm{~h}$ for the removal of $\mathrm{Cr}(\mathrm{VI})$ in our experimental work.

\subsubsection{Effect of Adsorbent Dosage}

Under optimized condition of $\mathrm{pH}$ and contact time, adsorption behaviors onto adsorbents at different dosages from $0.1 \mathrm{~g} \cdot \mathrm{dm}^{-3}$ to $2.0 \mathrm{~g} \cdot \mathrm{dm}^{-3}$ have been studied in $100 \mu \mathrm{g} \cdot \mathrm{dm}^{-3}$ of $\mathrm{Cr}$ solution. The removal of $\mathrm{Cr}(\mathrm{VI})$ more than $90 \%$ was observed for $1.0 \mathrm{~g} \cdot \mathrm{dm}^{-3}$ dosage, but no remarkable increase is observed at a dosage more than $1.0 \mathrm{~g} \cdot \mathrm{dm}^{-3}$. Therefore, $1.0 \mathrm{~g} \cdot \mathrm{dm}^{-3}$ was considered as optimum dosage for the removal of $\mathrm{Cr}(\mathrm{VI})$ in the study.

\subsection{Effect of Initial Concentration}

Study was carried out by varying initial concentrations from $20 \mu \mathrm{g} \cdot \mathrm{dm}^{-3}$ to $200 \mu \mathrm{g} \cdot \mathrm{dm}^{-3}$ under 
optimized conditions of $\mathrm{pH} 4$, contact time (i.e., time $4 \mathrm{~h}$ ) and adsorbent dosage (i.e., $1.0 \mathrm{~g} \cdot \mathrm{dm}^{-3}$ ). There was a continuous increase in the uptake of $\mathrm{Cr}(\mathrm{VI})$ per gram of adsorbent up to the concentration of $100 \mu \mathrm{g} \cdot \mathrm{dm}^{-3}$, but the uptake is almost constant at further higher concentration for $\mathrm{Cr}(\mathrm{VI})$. Data obtained from the variation of initial concentrations were fitted for adsorption isotherms [9] to estimate the relevant parameters mentioned in Section 2.4.

\subsection{Adsorption Isotherms}

Adsorption isotherms are commonly used to reflect the performance of adsorbents in adsorption processes. The adsorption data obtained for $\mathrm{Cr}(\mathrm{VI})$ using zeolite, chitosan and ZCHC were analyzed by Langmuir (Fig. 4) and Freundlich equations. The correlation coefficients $\left(R^{2}\right)$ of these isotherms for $\mathrm{Cr}(\mathrm{VI})$ on each adsorbent are shown in Table 2 along with other relevant parameters.

From Table 2, it is found that $R^{2}$ value for $\mathrm{Cr}(\mathrm{VI})$ on each adsorbent is comparatively large, and favorable adsorption of $\mathrm{Cr}$ by adsorbents were presented. Particularly, $R^{2}$ values in Langmuir isotherm are large for any $\mathrm{Cr}(\mathrm{VI})$. This result suggests that the adsorption of $\mathrm{Cr}(\mathrm{VI})$ on chitosan or ZCHC mainly occurred by monolayer reaction.

\subsection{Kinetic Studies}

The linear plot of $t / q_{t}$ versus time $t$ for $\mathrm{Cr}(\mathrm{VI})$ adsorption under the optimized experimental conditions is shown in Fig. 5. The pseudo-second-order rate constant $(k)$ and the amount of adsorbed lead $\left(q_{\mathrm{e}}\right)$, obtained from the intercept and slope of the plot of $t / q_{t}$ vs. $t$ are listed in Table 3 along with the regression coefficients $\left(R^{2}\right)$. It implies that the adsorption kinetics based on the experimental values are in good agreement with the pseudo second-order kinetic model. The intraparticle diffusion model indicated that the relationship between the concentration of $\mathrm{Cr}(\mathrm{VI})$ and the square root of time are linear. This suggests that the adsorption process could be controlled by intraparticle diffusion.

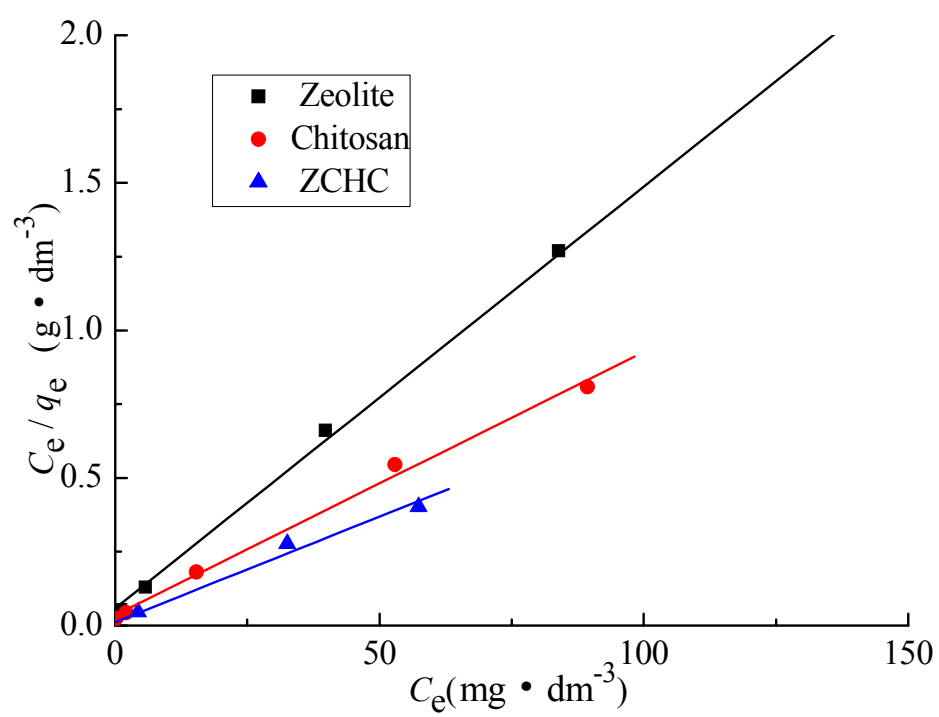

Fig. 4 Langmiur isotherm of $\mathrm{Cr}(\mathrm{VI})$ adsorption onto adsorbents.

Table 2 Coefficient of Langmuir and Freundlich isotherms for $\mathrm{Cr}(\mathrm{VI})$.

\begin{tabular}{lllllll}
\hline & \multicolumn{5}{l}{ Langmuir isotherm } & \multicolumn{5}{l}{ Freundlich isotherm } \\
\cline { 2 - 7 } & $\begin{array}{l}q_{\max } \\
\left(\mu \mathrm{g}^{-1}\right)\end{array}$ & $\begin{array}{l}K_{\mathrm{L}} \\
\left(\mathrm{dm}^{-3} \cdot \mu \mathrm{g}^{-1}\right)\end{array}$ & $R^{2}$ & $\begin{array}{l}K_{\mathrm{F}} \\
\left(\left(\mu \mathrm{g} \cdot \mathrm{g}^{-1}\right) \cdot\left(\mathrm{dm}^{-3} \cdot \mu \mathrm{g}^{-1}\right)^{1 / n}\right)\end{array}$ & $1 / n$ & $R^{2}$ \\
\hline Zeolite & 70.0 & 0.245 & 0.999 & 17.4 & 0.526 & 0.957 \\
Chitosan & 92.2 & 0.253 & 0.998 & 30.6 & 0.311 & 0.964 \\
ZCHC & 109 & 0.645 & 0.994 & 57.7 & 0.237 & 0.955 \\
\hline
\end{tabular}




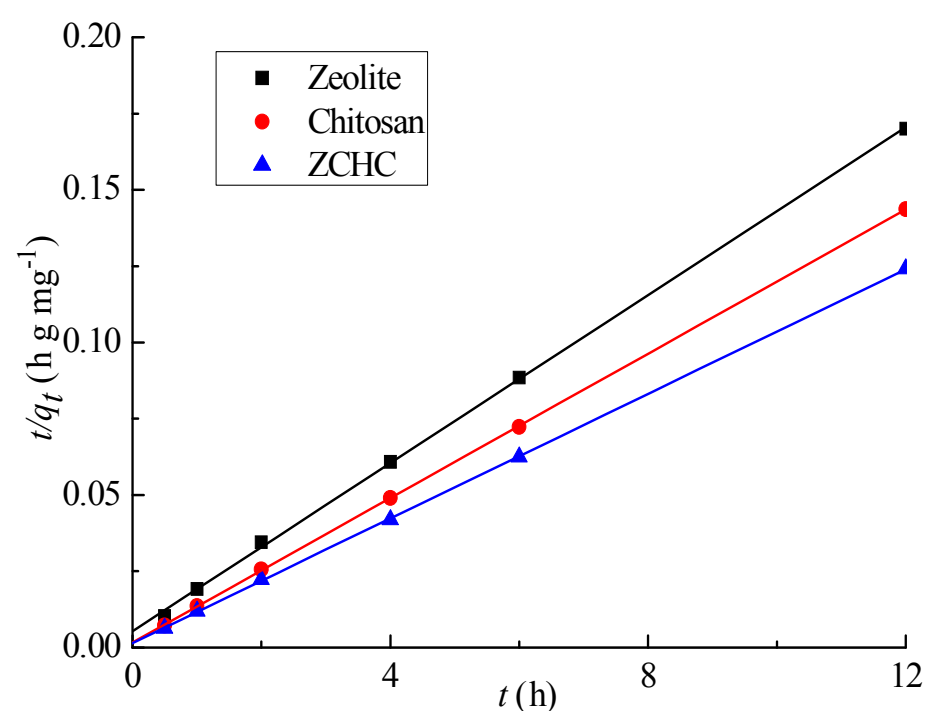

Fig. 5 The pseudo-second-order kinetic model for adsorbents.

Table 3 Kinetic coefficient for $\mathrm{Cr}(\mathrm{VI})$ adsorption on adsorbents.

\begin{tabular}{llll}
\hline Adsorbents & $\begin{array}{l}q_{\mathrm{e}} \\
\left(\mu \mathrm{g} \cdot \mathrm{g}^{-1}\right)\end{array}$ & $\begin{array}{l}k \\
\left(\mathrm{~g} \cdot \mathrm{mol}^{-1} \cdot \mathrm{h}^{-1}\right)\end{array}$ & $R$ \\
\hline Zeolite & 72.6 & 0.0351 & 0.999 \\
Chitosan & 84.5 & 0.0724 & 0.999 \\
ZCHC & 97.9 & 0.0869 & 0.999 \\
\hline
\end{tabular}

\section{Conclusions}

The aim of this investigation was to prepare and characterize a ZCHC, and investigate the ability of this hybrid composite to be used for $\mathrm{Cr}(\mathrm{VI})$ removal. The hybrid composite exhibits higher adsorption capacity and stronger chemical affinity than pristine zeolite and chitosan.

The isotherm models such as Langmuir and Freundlich were used to analyze the adsorption data. The adsorption of $\mathrm{Cr}(\mathrm{VI})$ by the $\mathrm{ZCHC}$ was well fitted to Langmuir isotherms, which suggests that the adsorption of $\mathrm{Cr}(\mathrm{VI})$ on ZCHC mainly occurred by monolayer reaction. The kinetic studies of $\mathrm{Cr}(\mathrm{VI})$ adsorption by the ZCHC was analyzed using the pseudo-first order and pseudo-second order kinetic models, and it shows better fitting for the pseudo-second order of $\mathrm{Cr}(\mathrm{VI})$ adsorption.

From the above results, ZCHC (which was prepared with sol-gel method by mixing zeolite and chitosan) can be an effective adsorbent for $\mathrm{Cr}(\mathrm{VI})$ from aqueous solution. This provides very significant information from the viewpoint of environmental protection.

\section{Acknowledgments}

The present work was partially supported by a Grant-in-Aid for Scientific Research (Research Program (C), No. 25340083) of the Japan Society for the Promotion of Science. This research was also supported by a fund for the promotion of Niigata University KAAB Projects from the Ministry of Education, Culture, Sports, Science and Technology, Japan.

The authors are also grateful to Dr. K. Fujii and Mr. M. Ohizumi of Office for Environment and Safety in Niigata University, Mr. T. Hatamachi, Mr. T. Nomoto and Prof. T. Tanaka and of Fac. of Eng. in Niigata University for permitting the use of ICP-AES, Surface Area Analyzer and SEM for giving helpful advice in measurement.

\section{References}

[1] Saether, O. M., Storroe, G., Segar, D., and Krog, R. 1997. "Contamination of Soil and Groundwater at a Former 
Industrial Site in Trondheim, Norway." Applied Geochemistry 12: 327-32.

[2] Dahiya, S., Tripathi, R. M., and Hegde, A. G. 2008. "Biosorption of Heavy Metals and Radionuclide from Aqueous Solutions by Pre-treated Arca Shell Biomass." $J$. Hazard. Mater. 150: 376-86.

[3] Pillai, S. S., Mullassery, M. D., Fernandez, N. B., Girija, N. Geetha, P., and Koshy, M. 2013. "Biosorption of $\mathrm{Cr}(\mathrm{VI})$ from Aqueous Solution by Chemically Modified Potato Starch: Equilibrium and Kinetic Studies." Ecotoxicology and Environmental Safety 92: 199-205.

[4] Chauhan, D., Jaiswal, M., and Nalini, S. 2012. "Removal of Cadmium and Hexavalent Chromium from Electroplating Wastewater Using Thiocarbamoyl Chitosans." Carbohydrate Polymers 88: 670-5.

[5] Kousalya, G. N., Gandhi, M. R., and Meenakshi, S. 2010. "Sorption of Chromium (VI) Using Modified Forms of Chitosan Beads." International Journal of Biological Macromolecules 47: 308-15.

[6] Motomizu, S., Jitmanee, K., and Oshima, M. 2003. "On-Line Collection/Concentration of Trace Metals for Spectroscopic Detection via Use of STSP (Small-Sized Thin Solid Phase) Column Resin Reactors, Application to Speciation of $\mathrm{Cr}(\mathrm{III})$ and $\mathrm{Cr}(\mathrm{VI})$." Analytica Chimica Acta 499: 149-55.

[7] Fukushima, M., Nakayasu, K., Tanaka, S., and Nakamura, H. 1997. "Speciation Analysis of Chromium after Reduction of Chromium (VI) by Humic Acid." Txicological and Environmental Chemistry 62: 207-15.

[8] Donais, M. K., Henry, R., and Rettberg, T. 1999. "Chromium Speciation Using an Automated Liquid Handling System with Inductively Coupled Plasma-Mass Spectrometric Detection.” Talanta 49: 1045-50.

[9] Acosta, R. I., Rodriguez, X., Gutierrez, C., and Guadalupe, M. M. 2004. "Biosorption of Chromium (VI) from Aqueous Solutions onto Fungal Biomass." Bioinorganic Chemistry and Application 2: 1-7.

[10] Mungasavalli, D. P., Viraraghavan, T., and Jin, Y. C. 2007. "Biosorption of Chromium from Aqueous Solutions by Pretreated Aspergillus Niger: Batch and Column Studies." Colloids and Surfaces A: Physicochemical and Engineering Aspects 301: 214-23.

[11] Ertugay, N., and Bayhan, Y. K. 2008. "Biosorption of Cr (VI) from Aqueous Solutions by Biomass of Agaricus Bisporus." Journal of Hazardous Materials 154: 432-9.

[12] Wan Ngah, W. S., Teong, L. C., Toh, R. H., and Hanafiah, M. A. K. M. 2012. "Utilization of Chitosan-zeolite Composite in the Removal of $\mathrm{Cu}$ (II) from Aqueous Solution: Adsorption, Desorption and Fixed Bed Column Studies." Chemical Engineering Journal 209: 46-53.

[13] Xie, J., Li, C., Chi, L., and Wu, D. 2013. "Chitosan Modified Zeolite as a Versatile Adsorbent for the
Removal of Different Pollutants from Water.” Fuel 103: 480-5.

[14] Rahmati, M. M., Rabbani, P., Abdolali, A., and Keshtkar, A. R. 2011. "Kinetics and Equilibrium Studies on Biosorption of Cadmium, Lead and Nickel Ions from Aqueous Solutions by Intact and Chemically Modified Brown Algae." Journal of Hazardous Materials 185: 401-7.

[15] Mohantly, K., Jha, M., Meikap, B. C., and Biswas, M. N. 2006. "Biosorption of Lanthanides Using Three Kinds of Seaweed Biomasses." Chemical Engineering Journal 117: 71-7.

[16] Kumar, R., Bishnoi, N. R., and Bishnoi, G. K. 2008. "Biosorption of Chromium (VI) from Aqueous Solution and Electroplating Wastewater Using Fungal Biomass." Chemical Engineering Journal 135: 202-8.

[17] Dahiya, S., Tripathi, R. M., and Hegde, A. G. 2008. "Biosorption of Lead and Copper from Aqueous Solutions by Pre-treated Crab and Arca Shell Biomass." Bioresource Technology 99: 179-87.

[18] Wan Ngah, W. S., and Fatinathan, S. 2010. "Pb(II) Biosorption Using Chitosan and Chitosan Derivatives Beads: Equilibrium, Ion Exchange and Mechanism Studies." Journal of Environmental Sciences 22: 338-46.

[19] Gerente, C., Lee, V. C., Cloirec, P. L., and McKay, G. 2007. "Application of Chitosan for the Removal of Metals from Wastewaters by Adsorption-Mechanisms and Models Review." Critical Reviews in Environmental Science and Technology 37: 41-127.

[20] Wang, G., Liu, J., Wang, X., Xie, Z. Y., and Deng, N. 2009. "Adsorption of Uranium (VI) from Aqueous Solution onto Cross-Linked Chitosan." Journal of Hazardous Materials 168: 1053-8.

[21] Wan, W. S., Teong, L. C., and Hanafiah, M. A. 2011. "Adsorption of Dyes and Heavy Metal Ions by Chitosan Composites: A Review." Carbohydrate Polymers 83: 1446-56.

[22] Liu, B., Lv, X., Meng, X., Yu, G., and Wang, D. 2013. "Removal of $\mathrm{Pb}$ (II) from Aqueous Solution Using Dithiocarbamate Modified Chitosan Beads with $\mathrm{Pb}(\mathrm{II})$ as Imprinted Ions." Chemical Engineering Journal 220: 412-9.

[23] Xu, D., Tan, X. L., Chen, C. L., and Wang, X. K. 2008. "Adsorption of $\mathrm{Pb}$ (II) from Aqueous Solution to MX-80 Bentonite: Effect of $\mathrm{pH}$, Ionic Strength, Foreign Ions and Temperature." Appl. Clay Sci. 41: 37-46.

[24] Aksu, Z., Acikel, U., Kabasakal, E., and Tezer, S. 2002. "Equilibrium Modelling of Individual and simultaneous Biosorption of Chromium (VI) and Nickel (II) onto Dried Activated Sludge." Water Research 36: 3063-73.

[25] Salgado-Gómez, N., Macedo-Miranda, M. G., and Olguín, 
M. T. 2014. "Chromium (VI) Adsorption from Sodium Chromate and Potassium Dichromate Aqueous Systems by Hexadecyltrimethylammonium-modified Zeolite-rich Tuff." Appl. Clay Sci. 95: 197-204.

[26] Hamadi, N. K., Chen, X. D., Farid, M. M., and Lu, M. Q. 2001. "Adsorption Kinetics for the Removal of Chromium (VI) from Aqueous Solution by Adsorbents
Derived from Used Tyres and Sawdust." Chemical Engineering Journal 84: 95-105.

[27] Duranoglu, D., Trochimczuk, A. W., and Beker, U. 2012. "Kinetics and Thermodynamics of Hexavalent Chromium Adsorption onto Activated Carbon Derived from Acrylonitrile-Divinylbenzene Copolymer." Chemical Engineering Journal 187: 193-202. 